\title{
Investigation of Vibratory Detection Thresholds on Proximal Phalange and Wrist in Blind and Visually Impaired Teenagers
}

\author{
E. Bogusz*, G. Mrozik And E. SkrodzkA \\ Institute of Acoustics, A. Mickiewicz University, Umultowska 85, 61-614 Poznań, Poland
}

\begin{abstract}
The paper presents results concerning vibratory detection thresholds measured on a wrist and proximal phalange and fingertips of the index, middle and ring fingers for blind and visually impaired teenagers. Subjects with vision dysfunctions were divided into two groups: congenitally blind and visually impaired. The study tested 10 handicapped individuals ( 5 congenitally blind and 5 visually impaired) and 10 sighted persons making reference groups chosen to be adequate in terms of age, gender, body mass and height. To date, no study has described results of such experiments for blind/visually handicapped teenagers. Vibratory perception thresholds were tracked using the Bekesy algorithm. The thresholds were investigated as a function of stimulating force frequency and magnitude or an area of a stimulating probe. Threshold values obtained for the wrist were higher than values obtained for proximal phalange and fingertips. It was shown that the performance of blind/visually impaired teenagers was not better than their sighted counterparts. Suggestions about technical form and physical parameters of a vibrating device signalling places particularly dangerous for blind/visually handicapped people were formulated.
\end{abstract}

PACS: $43.66 . \mathrm{Wv}$

\section{Introduction}

Measuring cutaneous sensitivity to tactile stimuli presented an interesting challenge to many investigators and led to a detailed description of mechanoreceptive systems of skin [1]. Measurements of vibratory perception thresholds have been widely used for early detection of peripheral nervous system disorders, like vibration syndrome or peripheral neuropathies $[2,3]$. The effect of aging on vibration detection thresholds was carefully examined, too $[2,4]$. Some papers concern sensitivity to vibration of deaf children and adults $[5,6]$. A number of studies have shown that adult blind or visually handicapped people perform better than sighted individuals in some auditory tasks [7-11]. Only a few papers report enhanced tactile perception in the blind [12-14], none of them concerning blind or visually handicapped teenagers.

It is known that the matured central nervous system is capable of undergoing plastic changes. Alteration of inputs to the central nervous system may occur not only as a result of peripheral or central lesions, but also following increased stimulation of a particular body region. It is an evidence of possibilities of vibrational signal application for the orientation and mobility of blind and visually impaired people after a proper training. Therefore, investigation of vibratory detection thresholds on the wrist and proximal phalange, as possible places of application of tactile signalling devices, is very important.

* corresponding author; e-mail: ebogusz@amu.edu.pl
The main aim of presented work is to evaluate the vibratory perception thresholds on the wrist and proximal phalange in blind and visually impaired teenagers. The relevant data in literature are very scanty and incomplete [15-17]. Results presented in this work may be a basis for a choice of optimal physical parameters generated by a non-audible vibrating device signalling places particularly dangerous for blind or visually challenged people.

\section{Subjects}

A total of 10 blind/visually impaired teenagers and 10 sighted reference persons took part in the experiment. All our handicapped subjects had problems with vision from birth or soon after it, i.e. they were congenitally or early blind individuals. There were 5 blind individuals (4 congenitally blind and 1 early-blind) and 5 visually impaired subjects. The only early blind girl was included to congenitally blind group.

Table I shows demographic characteristics of subjects with vision dysfunctions. For each blind participant a sighted control person was recruited, of the same age, gender, body mass and height. All subjects were volunteers, they were not paid for their cooperation and they had no previous experience in vibrotactile experiments. The blind/visually impaired subjects were recruited from the Special Training and Education Centre for Blind Children in Owińska, Poland. All were free of neurological effects. They could stop testing in any time, when they felt tired or uncomfortable. 
TABLE I

Characteristics of the visually handicapped group.

$\mathrm{CB}$ - congenitally blind, B - blind,

VI - visually impaired.

\begin{tabular}{c|c|c|c}
\hline \hline $\begin{array}{c}\text { Blindness group } \\
\text { /Subject }\end{array}$ & Age at test & $\begin{array}{c}\text { Age of blindness } \\
\text { onset [yrs] }\end{array}$ & Gender \\
\hline CB_1 & 12 & 0 & male \\
CB_2 & 15 & 0 & female \\
CB_3 & 15 & 0 & female \\
B_-4 & 15 & 9 & female \\
CB_5 & 16 & 0 & male \\
VI_1 & 13 & 0 & female \\
VI_2 & 15 & 0 & male \\
VI_3 & 16 & 0 & male \\
VI_4 & 17 & 0 & female \\
VI_5 & 17 & 0 & female
\end{tabular}

\section{Experiment}

Vibratory detection thresholds on proximal phalanges of the index, middle and ring fingers and on two sites on the wrist were measured in places shown in Fig. 1. Additionally, the thresholds were measured for the index, middle and ring fingertips in order to calibrate the measuring device.

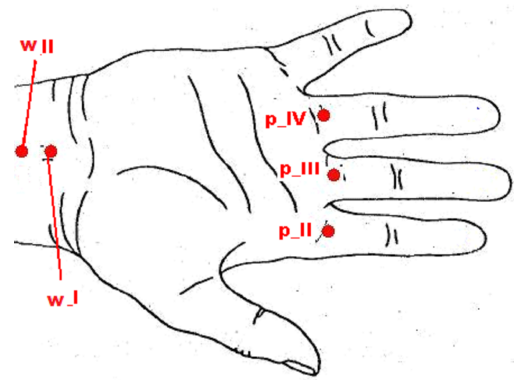

Fig. 1. Vibratory perception threshold measuring points. Letter "w" denotes the wrist points, letter "p" denotes points on proximal phalange.

Both hands were investigated. Vibratory detection thresholds were tracked using the Bekesy algorithm. The value of the detection threshold was an average from six turning points, differing by no more than $\pm 2 \mathrm{~dB}$ from the mean value. The measure of the detection threshold was acceleration level referenced to $10^{-6} \mathrm{~m} / \mathrm{s}^{2}$. Measurements were carried out at the frequencies of 4,25 , $32,63,125,250,400$, and $500 \mathrm{~Hz}$. Two force magnitudes and two sizes of the stimulating probe were used for each frequency $-0.1 \mathrm{~N}$ and $1.2 \mathrm{~N}$ for a probe of $5 \mathrm{~mm}$ diameter and $12 \mathrm{~mm}$ diameter, respectively. Pallesthesiometer EMSON-Mat P8 was used in the experiments [16]. All subjects were given several training trials to get familiar with the task before the main experiment.

\section{Results and discussion}

Measured detection threshold values together with standard deviations, in $\mathrm{dB}$ referenced to $10^{-6} \mathrm{~m} / \mathrm{s}^{2}$, are shown in Table II for blind and visually impaired persons and in Table III for appropriate reference groups. Tables II and III contain data shown in Figs. 2-4.

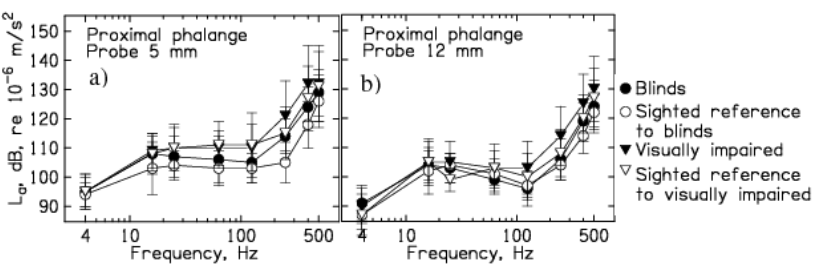

Fig. 2. Comparison of vibratory detection thresholds measured for proximal phalange for (a) the probe diameter $5 \mathrm{~mm}$ /force magnitude $0.1 \mathrm{~N}$, (b) the probe diameter $12 \mathrm{~mm} /$ force magnitude $1.2 \mathrm{~N}$



Fig. 3. Comparison of vibratory detection thresholds measured on the wrist for point I and (a) the probe diameter $5 \mathrm{~mm} /$ force magnitude $0.1 \mathrm{~N}$, (b) the probe diameter $12 \mathrm{~mm} /$ force magnitude $1.2 \mathrm{~N}$, for the point II and (c) the probe diameter $5 \mathrm{~mm} /$ force magnitude $0.1 \mathrm{~N}$, (d) the probe diameter $12 \mathrm{~mm} /$ force magnitude $1.2 \mathrm{~N}$.

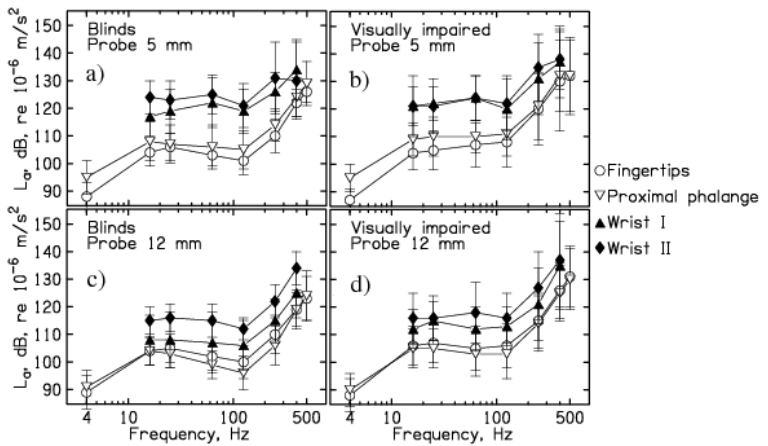

Fig. 4. Comparison of vibratory detection thresholds measured on fingertips, proximal phalange and two points on the wrist for four groups of subjects (blind, visually impaired and their reference groups) and two probe sizes/force magnitudes. 
TABLE II

Detection threshold values together with standard deviations (in $\mathrm{dB}$ referenced to $10^{-6} \mathrm{~m} / \mathrm{s}^{2}$ ) for blind and visually impaired persons.

\begin{tabular}{|c|c|c|c|c|c|c|c|c|}
\hline & \multicolumn{8}{|c|}{ Blinds, probe $5 \mathrm{~mm}$} \\
\hline & $4 \mathrm{~Hz}$ & $16 \mathrm{~Hz}$ & $25 \mathrm{~Hz}$ & $63 \mathrm{~Hz}$ & $125 \mathrm{~Hz}$ & $250 \mathrm{~Hz}$ & $400 \mathrm{~Hz}$ & $500 \mathrm{~Hz}$ \\
\hline Fingertips & $88, \mathrm{sd}=5$ & $104, \mathrm{sd}=5$ & $106, \mathrm{sd}=5$ & $103, \mathrm{sd}=4$ & $101, \mathrm{sd}=5$ & $110, \mathrm{sd}=6$ & $122, \mathrm{sd}=5$ & $126, \mathrm{sd}=4$ \\
\hline $\begin{array}{l}\text { Proximal } \\
\text { phalange }\end{array}$ & $95, \mathrm{sd}=6$ & $108, \mathrm{sd}=7$ & $107, \mathrm{sd}=7$ & $106, \mathrm{sd}=8$ & $105, \mathrm{sd}=7$ & $114, \mathrm{sd}=6$ & $124, \mathrm{sd}=7$ & $129, \mathrm{sd}=8$ \\
\hline Wrist I & & $117, \mathrm{sd}=7$ & $119, \mathrm{sd}=8$ & $122, \mathrm{sd}=9$ & $119, \mathrm{sd}=8$ & $126, \mathrm{sd}=7$ & $134, \mathrm{sd}=11$ & \\
\hline \multirow[t]{3}{*}{ Wrist II } & & $124, \mathrm{sd}=6$ & $123, \mathrm{sd}=7$ & $125, \mathrm{sd}=7$ & $121, \mathrm{sd}=8$ & $131, \mathrm{sd}=13$ & $130, \mathrm{sd}=14$ & \\
\hline & \multicolumn{8}{|c|}{ Blinds, probe $12 \mathrm{~mm}$} \\
\hline & $4 \mathrm{~Hz}$ & $16 \mathrm{~Hz}$ & $25 \mathrm{~Hz}$ & $63 \mathrm{~Hz}$ & $125 \mathrm{~Hz}$ & $250 \mathrm{~Hz}$ & $400 \mathrm{~Hz}$ & $500 \mathrm{~Hz}$ \\
\hline Fingertips & $89, \mathrm{sd}=6$ & $104, \mathrm{sd}=5$ & $105, \mathrm{sd}=5$ & $102, \mathrm{sd}=5$ & $100, \mathrm{sd}=6$ & $110, \mathrm{sd}=7$ & $119, \mathrm{sd}=7$ & $123, \mathrm{sd}=8$ \\
\hline $\begin{array}{l}\text { Proximal } \\
\text { phalange }\end{array}$ & $91, \mathrm{sd}=6$ & $104, \mathrm{sd}=5$ & $103, \mathrm{sd}=5$ & $99, \mathrm{sd}=5$ & $96, \mathrm{sd}=6$ & $106, \mathrm{sd}=7$ & $119, \mathrm{sd}=6$ & $124, \mathrm{sd}=9$ \\
\hline Wrist I & & $108, \mathrm{sd}=9$ & $108, \mathrm{sd}=10$ & $107, \mathrm{sd}=11$ & $106, \mathrm{sd}=9$ & $115, \mathrm{sd}=8$ & $125, \mathrm{sd}=9$ & \\
\hline \multirow[t]{3}{*}{ Wrist II } & & $115, \mathrm{sd}=5$ & $116, \mathrm{sd}=5$ & $115, \mathrm{sd}=6$ & $112, \mathrm{sd}=4$ & $122, \mathrm{sd}=6$ & $134, \mathrm{sd}=6$ & \\
\hline & \multicolumn{8}{|c|}{ Visually impaired, probe $5 \mathrm{~mm}$} \\
\hline & $4 \mathrm{~Hz}$ & $16 \mathrm{~Hz}$ & $25 \mathrm{~Hz}$ & $63 \mathrm{~Hz}$ & $125 \mathrm{~Hz}$ & $250 \mathrm{~Hz}$ & $400 \mathrm{~Hz}$ & $500 \mathrm{~Hz}$ \\
\hline Fingertips & $87, \mathrm{sd}=4$ & $104, \mathrm{sd}=6$ & $105, \mathrm{sd}=7$ & $107, \mathrm{sd}=8$ & $108, \mathrm{sd}=9$ & $120, d=13$ & $130, \mathrm{sd}=18$ & $132, \mathrm{sd}=14$ \\
\hline $\begin{array}{l}\text { Proximal } \\
\text { phalange }\end{array}$ & $95, \mathrm{sd}=5$ & $109, \mathrm{sd}=6$ & $110, \mathrm{sd}=7$ & $110, \mathrm{sd}=6$ & $110, \mathrm{sd}=8$ & $121, d=12$ & $132, \mathrm{sd}=13$ & $132, \mathrm{sd}=13$ \\
\hline Wrist I & & $121, \mathrm{sd}=7$ & $122, \mathrm{sd}=6$ & $124, \mathrm{sd}=8$ & $120, \mathrm{sd}=11$ & $131, \mathrm{sd}=13$ & $137, \mathrm{sd}=13$ & \\
\hline \multirow[t]{3}{*}{ Wrist II } & & $121, \mathrm{sd}=11$ & $121, \mathrm{sd}=10$ & $124, \mathrm{sd}=8$ & $122, \mathrm{sd}=10$ & $135, \mathrm{sd}=12$ & $138, \mathrm{sd}=11$ & \\
\hline & \multicolumn{8}{|c|}{ Visually impaired, probe $12 \mathrm{~mm}$} \\
\hline & $4 \mathrm{~Hz}$ & $16 \mathrm{~Hz}$ & $25 \mathrm{~Hz}$ & $63 \mathrm{~Hz}$ & $125 \mathrm{~Hz}$ & $250 \mathrm{~Hz}$ & $400 \mathrm{~Hz}$ & $500 \mathrm{~Hz}$ \\
\hline Fingertips & $88, \mathrm{sd}=6$ & $106, \mathrm{sd}=7$ & $107, \mathrm{sd}=7$ & $105, \mathrm{sd}=8$ & $106, \mathrm{sd}=8$ & $115, \mathrm{sd}=10$ & $126, \mathrm{sd}=10$ & $131, \mathrm{sd}=11$ \\
\hline $\begin{array}{l}\text { Proximal } \\
\text { phalange }\end{array}$ & $90, \mathrm{sd}=6$ & $105, \mathrm{sd}=7$ & $105, \mathrm{sd}=7$ & $103, \mathrm{sd}=8$ & $103, \mathrm{sd}=9$ & $114, \mathrm{sd}=10$ & $125, \mathrm{sd}=10$ & $130, \mathrm{sd}=11$ \\
\hline Wrist I & & $112, \mathrm{sd}=7$ & $115, \mathrm{sd}=7$ & $112, \mathrm{sd}=8$ & $113, \mathrm{sd}=7$ & $121, \mathrm{sd}=13$ & $135, \mathrm{sd}=16$ & \\
\hline Wrist II & & $116, \mathrm{sd}=9$ & $116, \mathrm{sd}=8$ & $118, \mathrm{sd}=11$ & $116, \mathrm{sd}=9$ & $127, \mathrm{sd}=13$ & $137, \mathrm{sd}=17$ & \\
\hline
\end{tabular}

The primary dependent variable was the vibratory detection threshold value. Analysis of variance was performed to find statistically significant factors and differences between four groups of participants (congenitally blind, visually impaired, the sighted reference group for the congenitally blind subjects and the sighted reference group for the visually impaired teenagers). Before ANOVA calculations non-parametric normality tests were performed for all compared groups. According to them our results had normal distribution $(p>0.2$ for the Kolmogorov-Smirnov test, $p>0.2$ for the Lilliefors test and $p>0.05$ for the Shapiro-Wilk test). Only in a few cases the normal distribution was not confirmed. In such cases skewness coefficients were examined. The examination shows that the distribution of questionable data was normal or quasi-normal.

No statistically significant differences in the means were found for all investigated fingertips on both hands and for both probe diameters/force magnitudes, for the congenitally blind group, visually impaired individuals, both reference groups and between groups. The threshold values were similar to those reported in literature for adults without vision problems [15-17].

For proximal phalange the only statistically significant factor was the diameter/force magnitude $(p<0.0005, p$ - significance level) for both groups of visually handicapped and their reference groups of sighted teenagers.
Thus, threshold values for proximal phalange depended on the probe diameter - they were slightly lower for the probe size $12 \mathrm{~mm}$ in the middle frequency range. The mean results of vibratory detection thresholds measured on proximal phalange are plotted in Fig. 2a, b. The acceleration level referred to $10^{-6} \mathrm{~m} / \mathrm{s}^{2}$ is denoted as $L_{\mathrm{a}}$ in all figures below. Error bars denote standard deviation of the mean. As no statistically significant differences were found for the investigated proximal phalange, averaged data for blind subjects, visually impaired persons and appropriate reference groups of sighted teenagers are shown in Fig. 2a, b for the probe of 5 and $12 \mathrm{~mm}$ in diameter, respectively. For both probe sizes/force magnitudes no difference between threshold values was observed for both handicapped groups and their sighted counterpart groups, as well as between the blind and visually impaired group.

Results of vibratory threshold measurements performed on two points on the wrist are shown in Fig. 3a-d. Values for the frequencies $4 \mathrm{~Hz}$ and $500 \mathrm{~Hz}$ are not shown. They were eliminated from the pattern of results because for the frequency $4 \mathrm{~Hz}$ the threshold values were lower than the lowest acceleration level generated by the measuring device. The frequency $500 \mathrm{~Hz}$ was excluded from analysis because the threshold values were higher than the highest level generated by the pallestesiometer. Additionally, for $500 \mathrm{~Hz}$ the device generated audible sound which could be an additional cue for subjects. 
TABLE III

Detection threshold values together with standard deviations (in $\mathrm{dB}$ referenced to $10^{-6} \mathrm{~m} / \mathrm{s}^{2}$ ) for sighted reference groups.

\begin{tabular}{|c|c|c|c|c|c|c|c|c|}
\hline & \multicolumn{8}{|c|}{ Sighted reference to blinds, probe $5 \mathrm{~mm}$} \\
\hline & $4 \mathrm{~Hz}$ & $16 \mathrm{~Hz}$ & $25 \mathrm{~Hz}$ & $63 \mathrm{~Hz}$ & $125 \mathrm{~Hz}$ & $250 \mathrm{~Hz}$ & $400 \mathrm{~Hz}$ & $500 \mathrm{~Hz}$ \\
\hline $\begin{array}{l}\text { Proximal } \\
\text { phalange }\end{array}$ & $94, \mathrm{sd}=4$ & $103, \mathrm{sd}=9$ & $104, \mathrm{sd}=5$ & $103, \mathrm{sd}=6$ & $103, \mathrm{sd}=5$ & $105, \mathrm{sd}=7$ & $118, \mathrm{sd}=8$ & $126, \mathrm{sd}=9$ \\
\hline Wrist I & & $113, \mathrm{sd}=11$ & $111, \mathrm{sd}=16$ & $117, \mathrm{sd}=11$ & $113, \mathrm{sd}=11$ & $119, \mathrm{sd}=9$ & $132, \mathrm{sd}=9$ & \\
\hline \multirow[t]{3}{*}{ Wrist II } & & $120, \mathrm{sd}=4$ & $118, \mathrm{sd}=12$ & $122, \mathrm{sd}=9$ & $121, \mathrm{sd}=6$ & $128, \mathrm{sd}=8$ & $138, \mathrm{sd}=5$ & \\
\hline & \multicolumn{8}{|c|}{ Sighted reference to blinds, probe $12 \mathrm{~mm}$} \\
\hline & $4 \mathrm{~Hz}$ & $16 \mathrm{~Hz}$ & $25 \mathrm{~Hz}$ & $63 \mathrm{~Hz}$ & $125 \mathrm{~Hz}$ & $250 \mathrm{~Hz}$ & $400 \mathrm{~Hz}$ & $500 \mathrm{~Hz}$ \\
\hline $\begin{array}{l}\text { Proximal } \\
\text { phalange }\end{array}$ & $87, \mathrm{sd}=8$ & $102, \mathrm{sd}=7$ & $104, \mathrm{sd}=4$ & $101, \mathrm{sd}=5$ & $97, \mathrm{sd}=4$ & $104, \mathrm{sd}=5$ & $114, \mathrm{sd}=6$ & $122, \mathrm{sd}=6$ \\
\hline Wrist I & & $105, \mathrm{sd}=7$ & $103, \mathrm{sd}=12$ & $103, \mathrm{sd}=7$ & $105, \mathrm{sd}=7$ & $111, \mathrm{sd}=4$ & $125, \mathrm{sd}=7$ & \\
\hline \multirow[t]{3}{*}{ Wrist II } & & $111, \mathrm{sd}=5$ & $111, \mathrm{sd}=8$ & $114, \mathrm{sd}=6$ & $111, \mathrm{sd}=5$ & $117, \mathrm{sd}=5$ & $133, \mathrm{sd}=6$ & \\
\hline & \multicolumn{8}{|c|}{ Sighted reference to visually impaired, probe $5 \mathrm{~mm}$} \\
\hline & $4 \mathrm{~Hz}$ & $16 \mathrm{~Hz}$ & $25 \mathrm{~Hz}$ & $63 \mathrm{~Hz}$ & $125 \mathrm{~Hz}$ & $250 \mathrm{~Hz}$ & $400 \mathrm{~Hz}$ & $500 \mathrm{~Hz}$ \\
\hline $\begin{array}{l}\text { Proximal } \\
\text { phalange }\end{array}$ & $95, \mathrm{sd}=6$ & $108, \mathrm{sd}=6$ & $110, \mathrm{sd}=8$ & $111, \mathrm{sd}=8$ & $111, \mathrm{sd}=11$ & $115, \mathrm{sd}=9$ & $127, \mathrm{sd}=11$ & $131, \mathrm{sd}=12$ \\
\hline Wrist I & & $118, \mathrm{sd}=6$ & $119, \mathrm{sd}=8$ & $116, \mathrm{sd}=7$ & $115, \mathrm{sd}=8$ & $122, \mathrm{sd}=8$ & $135, \mathrm{sd}=10$ & \\
\hline \multirow[t]{3}{*}{ Wrist II } & & $120, \mathrm{sd}=11$ & $118, \mathrm{sd}=11$ & $112, \mathrm{sd}=8$ & $118, \mathrm{sd}=7$ & $125, \mathrm{sd}=8$ & $137, \mathrm{sd}=10$ & \\
\hline & \multicolumn{8}{|c|}{ Sighted reference to visually impaired, probe $12 \mathrm{~mm}$} \\
\hline & $4 \mathrm{~Hz}$ & $16 \mathrm{~Hz}$ & $25 \mathrm{~Hz}$ & $63 \mathrm{~Hz}$ & $125 \mathrm{~Hz}$ & $250 \mathrm{~Hz}$ & $400 \mathrm{~Hz}$ & $500 \mathrm{~Hz}$ \\
\hline $\begin{array}{l}\text { Proximal } \\
\text { phalange }\end{array}$ & $87, \mathrm{sd}=5$ & $105, \mathrm{sd}=8$ & $99, \mathrm{sd}=4$ & $103, \mathrm{sd}=6$ & $100, \mathrm{sd}=8$ & $108, \mathrm{sd}=8$ & $120, \mathrm{sd}=8$ & $127, \mathrm{sd}=10$ \\
\hline Wrist I & & $112, \mathrm{sd}=9$ & $114, \mathrm{sd}=6$ & $112, \mathrm{sd}=8$ & $113, \mathrm{sd}=8$ & $119, \mathrm{sd}=13$ & $131, \mathrm{sd}=14$ & \\
\hline Wrist II & & $114, \mathrm{sd}=10$ & $115, \mathrm{sd}=8$ & $117, \mathrm{sd}=12$ & $116, \mathrm{sd}=9$ & $122, \mathrm{sd}=11$ & $131, \mathrm{sd}=15$ & \\
\hline
\end{tabular}

For both investigated points on the wrist the statistical analysis did not reveal statistical significance in the mean threshold values for the investigated point index (I or II) and the probe size of $5 \mathrm{~mm}$ for blind teenagers, visually impaired participants and their reference groups, Fig. 3a,b. The point index on the wrist and the probe size of $12 \mathrm{~mm}$ were the statistically significant factors for blind teenagers and their reference group $(p<0.0005)$ as well as for the sighted reference group for visually impaired $(p=0.010)$, Fig. 3c, d. Statistically significant differences in mean threshold values were found for point I and probe sizes 5 and $12 \mathrm{~mm}$, for congenitally blind subjects $(p<0.005)$, visually impaired individuals $(p=0.001)$, the reference group for congenitally blind persons $(p<0.005)$ and the reference group for visually impaired participants $(p=0.003)$, Fig. 3a,c. Similarly, for point II and probe sizes 5 and $12 \mathrm{~mm}$ statistically significant differences occurred for blind participants $(p=0.003)$ and their reference group $(p<0.0005)$, Fig. 3b, d. Both blind and visually handicapped subjects obtained higher threshold values for the probe size $5 \mathrm{~mm}$ than for the probe diameter $12 \mathrm{~mm}$.

Finally, comparison of the average threshold values for fingertips, proximal phalange and the wrist points I and II, for both handicapped groups and for two probe diameters/force magnitudes are shown in Fig. 4. For both compared groups no difference in threshold values for fingertips and proximal phalange for both applied probe sizes/force magnitudes was found. For blind and visually impaired subjects statistically significant differences (higher values) were revealed for threshold values mea- sured on proximal phalange and both points on the wrist for both probe sizes/force magnitudes $(p<0.0005$ for all cases). Higher threshold values found for the wrist can be explained by lower density of mechanoreceptors in the wrist skin [1].

It is clear from our results that the vibrating device signalling places particularly dangerous for blind or visually challenged people may have the form of a traditional ring or a bracelet. For the latter we recommend vibrating elements of diameter no smaller than $12 \mathrm{~mm}$ (low vibratory detection thresholds) and we do not recommend frequencies higher than $500 \mathrm{~Hz}$ because of a possible generation of audible sound. This frequency limit is not so strict for a ring because vibrating elements used in it are smaller in diameter and because of a small area they do not make too much noise. For both the ring and the bracelet, the acceleration levels should exceed detection thresholds of minimum $10 \mathrm{~dB}$.

It must be pointed that while the congenitally blind group of participants was a homogeneous group, the group of visually impaired subjects was not, because it consisted of persons having various degrees of vision loss and residual light perception.

This is the first study to test vibratory thresholds in proximal phalange and the wrist of blind and visually impaired teenagers as separate groups and compare them to the results for sighted individuals. Our results show that blindness or visual impairment does not necessary lead to superior performance in tactile detection tasks or that teenagers with vision disabilities do not obtain lower vibratory detection thresholds than sighted individuals of 
the same age. The opposite result was shown for the other type of experiments described in literature. It was found that the congenitally and early blind adult subjects were better than the adult sighted individuals in vibrotactile discrimination tasks [14]. It was suggested that adult blind subjects had greater experience with using vibrotactile information, related among others to the current Braille reading practice (hours per day). Our subjects were teenagers and not all of them were fluent in the Braille reading; nowadays blind teenagers prefer loud reading computer devices instead of the Braille reading.

\section{Conclusions}

We conclude that:

- Congenitally blind subjects and visually handicapped group do not perform better than their sighted reference groups.

- Vibratory detection thresholds for investigated fingertips and proximal phalange do not depend on the fingertip/phalanx index. The threshold values for fingertips are independent of the probe size. The threshold values for proximal phalange depend on the probe diameter they are slightly lower for the probe size $12 \mathrm{~mm}$ in the middle frequency range.

- Values of threshold are the same for fingertips and proximal phalanges for all tested frequencies and both probe sizes/force magnitudes and they are significantly lower from the thresholds measured in both points on the wrist.

- The threshold values obtained for the wrist point I (close to the palm), for the probe size $12 \mathrm{~mm}$, are lower than those obtained for the probe size $5 \mathrm{~mm}$ for blind subjects.

- Both a wrist and finger vibrating devices can be used as transducers signalling dangerous places in a city to visually handicapped people.

- Because of lower detection thresholds obtained for proximal phalange, a ring vibrating device is recommended when powering aspects are crucial.

- In the case of the wrist vibrating device, the frequency of $500 \mathrm{~Hz}$ seems to be not good, because perception threshold for the frequency are the highest and an audible acoustic signal is often associated to vibrations. The vibrating element should be positioned close to the palm.

- Irrespective of the technical solution of the signalling device, its acceleration level should exceed detection thresholds at least by $10 \mathrm{~dB}$.

\section{Acknowledgments}

We are very indebted to teachers and pupils of the Special Training and Education Centre for Blind Children in Owińska, Poland for their help, work, service and patience during experiments. The work was supported by the National Centre for Investigation and Development, grant N R17 0017 06, 2009-2012.

We are also much grateful to the two anonymous reviewers for their helpful comments and suggestions.

\section{References}

[1] S.J. Bolanowski, G.A. Gescheider, R.T. Verillo, C.M. Checkosky, J. Acoust. Soc. Am. 84, 1680 (1988).

[2] T. Skov, K. Steenland, J. Deddens, Am. J. Industr. Med. 34, 438 (1998).

[3] N. Harada, M. Griffin, Brit. J. Industr. Med. 48, 185 (1991).

[4] A.K. Goble, A.A. Collins, R.W. Cholewiak, J. Acoust. Soc. Am. 99, 2256 (1996).

[5] L.E. Bernstein, M.B. Schechter, M.H. Goldstein, J. Acoust. Soc. Am. 80, 118 (1986).

[6] T.M. Moallem, C.M. Reed, L.D. Braida, J. Acoust. Soc. Am. 127, 3696 (2010).

[7] F. Gougoux, F. Lepore, M. Lassonde, P. Voss, P.R.J. Zatorre, P. Belin, Nature 430, 309 (2004).

[8] N. Lessard, M. Pare, F. Lepore, M. Lassonde, Nature 395, 278 (1998).

[9] K. Hugdahl, M. Ek, F. Takio, T. Rintee, J. Tuomainen, C. Haarala, H. Hämäläinen, Cognit. Brain Res. 19, 28 (2004).

[10] A. Amedi, N. Raz, P. Pianka, R. Malach, E. Zohary, Nature Neurosci. 6, 758 (2003).

[11] C.Y. Wan, A.G. Wood, D.C. Reutens, S.J. Wilson, Neuropsychology 48, 344 (2010).

[12] D. Goldreich, I.M. Kanich, J. Neurosci. 23, 3439 (2003).

[13] B. Röder, F. Rösler, C. Spence, Current Biology 14, 121 (2004).

[14] C.Y. Wan, A.G. Wood, D.C. Reuters, S.J. Wilson, Neuropsychology 48, 631 (2010).

[15] J. Lofvenberg, R.S. Johansson, Brain Res. 301, 65 (1984).

[16] B. Harazin, A. Harazin-Lechowska, J. Kałamarz, G. Zieliński, Industr. Health 43, 535 (2005).

[17] E. Zamysłowska-Szmytke, M. Śliwińska-Kowalska, W. Szymczak, A. Dudarewicz, Med. Work 53, 397 (2002) (in Polish). 